\section{SEGITIGA DAN SEGIEMPAT PADA GEOMETRI DATAR EUCLID CEVIAN SEGITIGA DAN SEGIEMPAT SIKLIK}

\section{SAMSUMARLIN}

\begin{tabular}{ll}
\hline Keyword & Abstrak \\
\hline $\begin{array}{l}\text { Cevian, segiempat } \\
\text { siklik, sistem } \\
\text { deduktif.. }\end{array}$ & $\begin{array}{l}\text { Geometri Euclidean adalah sistem matematika yang dikaitkan dengan Euclid, } \\
\text { matematikawan dari Alexandria Yunani, yang dijelaskan dalam buku teksnya } \\
\text { pada geometri: The Elemen. Perkembangan geometri yang membuat } \\
\text { kajiannya lebih mendalam, mengakibatkan materi geometri sulit diajarkan } \\
\text { seluruhnya pada tingkat sekolah menegah. Tulisan ini khusus membahas } \\
\text { mengenai beberapa teorema terkait "cevian pada segitiga serta segiempat } \\
\text { siklik" dan disajikan secara deduktif. }\end{array}$ \\
\hline $\begin{array}{l}\text { Cevian, cyclic } \\
\text { quadrilateral, } \\
\text { deductive system. }\end{array}$ & $\begin{array}{l}\text { Euclidean geometry is a mathematical system attributed to Euclid, the Greek } \\
\text { mathematician from Alexandria, which is described in the textbook on } \\
\text { geometry: the Elements. The development of geometry which makes its study } \\
\text { more in-depth, hard geometry resulting material is taught entirely at the level } \\
\text { of secondary schools. This paper specifically discuss about some related } \\
\text { theorems "cevian on triangular and quadrilateral cyclic" and presented } \\
\text { deductively. }\end{array}$ \\
\hline
\end{tabular}

\section{PENDAHULUAN}

Meskipun banyak dari hasil Euclid telah dinyatakan oleh matematikawan sebelumnya, Euclid adalah yang pertama menunjukkan bagaimana proposisi bisa masuk ke dalam sebuah sistem deduktif dan logis komprehensif. The Elements dimulai dengan geometri bidang dan masih diajarkan di sekolah menengah sebagai sistem aksiomatik awal dan contoh awal dari pembuktian formal. Geometri datar ini berlanjut ke geometri tiga dimensi yang juga diajarkan pada sekolah menengah. Salah satu kajian dalam geometri bidang adalah tentang segitiga. Teorema-teorema terkait segitiga sebahagian diajarkan pada sekolah dalam domain geometri itu sendiri begitupula dalam domain trigonometri, seperti luasan daerah segitiga, aturan sinus, aturan kosinus, dan sebagainya. Sebahagian lagi ditemui dalam materi geometri pada perguruan tinggi dan beberapa diantaranya tetap diajarkan di sekolah hanya untuk kebutuhan-kebutuhan khusus, seperti pembelajaran pada kelas persiapan kometisi dan olimpiade.

Beberapa diantaranya akan diulas dalam tulisan ini, termasuk yang terkait dengan cevian segitiga. Cevian adalah setiap segmen garis dalam segitiga dengan salah satu titik ujung pada titik dari segitiga dan titik ujung lainnya pada sisi di 
depannya. Kajian terhadap cevian memunculkan banyak teorema diantaranya akan diulas dalam tulisan ini secara deduktif adalah teorema stewart, teorema ceva dan teorema. Selain itu akan diulas teorema terkait segiempat siklik (teorema Ptolemy) yaitu segiempat yang semua titik sudutnya $|B C|$

$\widehat{A B}$

$\mathrm{A}, \mathrm{B}, \mathrm{C} \quad$ Sudut $\angle B A C, \angle A B C$, dan $\angle A C B$ pada segitiga $\mathrm{ABC}$

$\mathrm{a}, \mathrm{b}, \mathrm{c}$

\section{Panjang BC}

Busur $\mathrm{AB}$

\section{PEMBAHASAN}

Teorema:

Suatu segitiga $\mathrm{ABC}$ dengan $\mathrm{D}$ adalah perpotongan garis tinggi dari $\mathrm{A}$ pada garis $\mathrm{BC}$, dan $\mathrm{P}$ titik sebarang pada segmen $\mathrm{BC}$, maka:

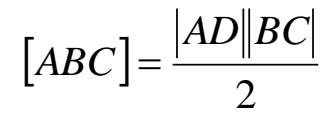

(2)

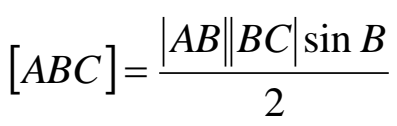

(3)

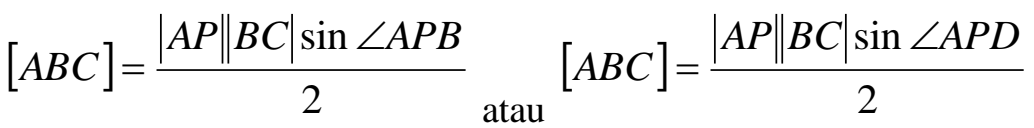

berada pada suatu lingkaran yang sama. Untuk memahami notasi yang digunakan dalam tulisan ini maka berikut disajikan beberapa notasi geometri beserta penjelasannya:

\section{$[A B C] \quad$ Luas daerah segitiga $\mathrm{ABC}$}

Bukti:

Misalkan $\mathrm{ABC}$ sebuah segitiga, dan misalkan D perpotongan tegak lurus ruas garis dari A ke garis $\mathrm{BC}$, seperti yang ditunjukkan pada Gambar 1.

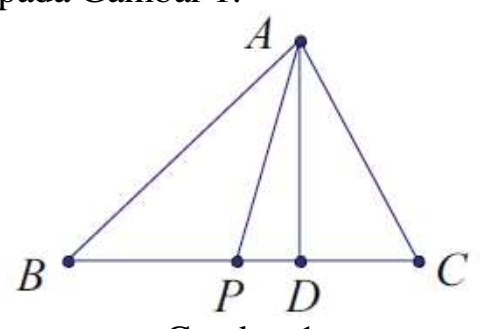

Gambar 1

Diperoleh luas daerah segitiga $\mathrm{ABC}$, yaitu $[A B C]=\frac{|A D \| B C|}{2}$. Perhatikan bahwa $|A D|=|A B| \sin B$, jadi $[A B C]=\frac{|A B \| B C| \sin B}{2}$.

Secara umum, jika $\mathrm{P}$ adalah titik pada segmen $\mathrm{BC}$, kemudian $|A D|=|A P| \sin \angle A P D$ atau $|A D|=|A P| \sin \angle A P B$ $\left.\sin \angle A P D=\sin \left(180^{\circ}-\angle A P B\right)=\sin \angle A P B\right)$.

Teorema:

Suatu segiempat $\mathrm{ABCD}$, dengan $\mathrm{P}$ titik perpotongan diagonal-diagonalnya, maka $[A B C D]=\frac{|A C \| B D| \sin \angle A P B}{2}$. 


\section{Bukti:}

Misalkan $\mathrm{ABCD}$ segiempat, dan misalkan $\mathrm{P}$ perpotongan diagonal $\mathrm{AC}$ dan $\mathrm{BD}$, seperti yang ditunjukkan pada Gambar 2.

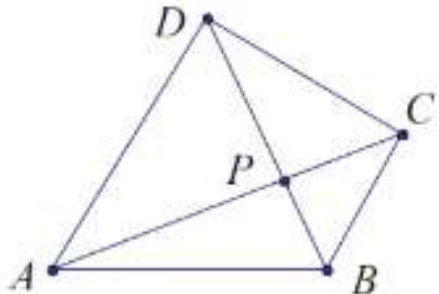

Gambar 2

$P D=\sin \left(180^{\circ}-\angle A P B\right)=\sin \angle A P B$, maka diperoleh

$[A B C D]=[A B C]+[A D C]$

$$
\begin{aligned}
& =\frac{|A C||B P| \sin \angle A P B}{2}+\frac{|A C||D P| \sin \angle A P B}{2} \\
& =\frac{|A C| \sin \angle A P B(|B P|+|D P|)}{2}
\end{aligned}
$$

$[A B C D]=\frac{|A C \| B D| \sin \angle A P B}{2}$

\section{Contoh Masalah (Aturan Sinus):}

Buktikan bahwa jika dimisalkan $\mathrm{ABC}$ suatu segitiga dengan $\mathrm{a}, \mathrm{b}$, dan $\mathrm{c}$ masing masing panjang segmen $\mathrm{BC}, \mathrm{AC}$, dan $\mathrm{AB}$, maka:

$$
\frac{a}{\sin A}=\frac{b}{\sin B}=\frac{c}{\sin C}
$$

\section{Bukti:}

Dengan menggunakan Teorema Daerah (2) maka dengan mudah kita menunjukkan bahwa:

$$
[A B C]=\frac{b c \sin A}{2}=\frac{a c \sin B}{2}=\frac{a b \sin C}{2}
$$

Dengan membagi kesamaan di atas dengan $\frac{a b c}{2}$, diperoleh

$$
\frac{\sin A}{a}=\frac{\sin B}{b}=\frac{\sin C}{c} \text { Atau } \frac{a}{\sin A}=\frac{b}{\sin B}=\frac{c}{\sin C}
$$

\section{TEOREMA PTOLEMY}

Dalam geometri Euclidean, teorema Ptolemy adalah hubungan antara empat sisi dan dua diagonal dari segiempat siklik (segiempat yang titik sudutnya terdapat pada lingkaran yang sama). Teorema ini dinamai dengan nama astronom dan matematika Yunani, Ptolemeus (Claudius Ptolemaeus).

Teorema Ptolemy secara verbal dapat dinyatakan sebagai berikut: "Jika segiempat terletak dalam lingkaran maka hasil kali dari diagonal-diagonalnya sama dengan jumlah dari hasil kali dari pasang sisi yang berhadapan".

Selain itu, kebalikan dari teorema Ptolemy juga benar, sebagai berikut: "Segiempat, jika jumlah hasil kali dari dua pasang sisi yang berhadapan adalah sama dengan hasil kali dari diagonal-diagonalnya, 
maka segiempat dapat dilukiskan pada sebuah lingkaran".

\section{Teorema Ptolemy:}

Jika segiempat dinyatakan dengan empat titik sudut A, B, C, dan D pada suatu lingkaran, maka:

$$
|A C||B D|=|A B\|C D|+| A D\| B C|
$$

Bukti:

Dengan menggunakan teorema luas. Dimisalkan suatu segiempat dengan titik sudutnya berada pada suatu lingkaran yang sama (diberi nama $\mathrm{A}, \mathrm{B}, \mathrm{C}$, dan $\mathrm{D}$ ), dengan $\mathrm{P}$ adalah perpotongan $\mathrm{AC}$ dan $\mathrm{BD}$, seperti pada Gambar 3 berikut:

$$
[A B C D]=\frac{1}{2}|A C \| B D| \sin \angle A P B
$$

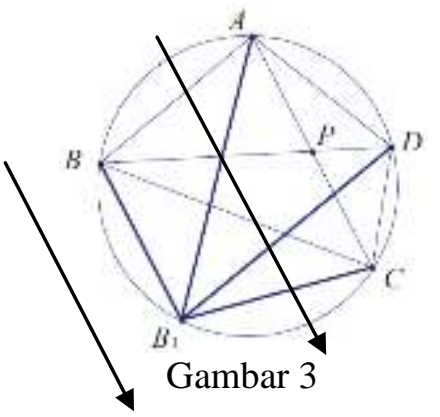

Kita refleksikan $\mathrm{B}$ sejajar dengan diagonal AC. Misal $\mathrm{B}_{1}$ bayangan $\mathrm{B}$ oleh refleksi. Maka $\mathrm{ABB}_{1} \mathrm{C}$ adalah trapesium sama kaki dengan $\mathrm{BB}_{1} \| \mathrm{AC},|A B|=\left|C B_{1}\right|$, dan $\left|A B_{1}\right|=|C B|$.

Selanjutnya $\widehat{A B}=\widehat{B_{1} C}$ sehingga

$$
\angle \mathrm{B}_{1} \mathrm{AD}=\frac{\widehat{\mathrm{B}_{1} \mathrm{D}}}{2}=\frac{\widehat{\mathrm{B}_{1} \mathrm{C}}+\widehat{\mathrm{CD}}}{2}=\frac{\widehat{\mathrm{AB}}+\widehat{\mathrm{CD}}}{2}=\angle \mathrm{APB}
$$

Karena $\mathrm{AB}_{1} \mathrm{CD}$ merupakan segiempat siklik, maka $\angle B_{1} A D+\angle B_{1} C D=180^{\circ}$, selanjutnya diperoleh $\sin \angle B_{1} A D=\sin \angle B_{1} C D=\sin \angle A P B$.

Perhatikan bahwa $A B C D \cong A B_{1} C D$, sehingga

$$
[A B C D]=\frac{1}{2} \sin \angle A P B(|A D\|B C|+| A B\| C D|)
$$

Dari (1) dan (2) diperoleh

$$
|A C\|B D|=| A B\| C D|+|A D \| B C|
$$

\section{Contoh masalah (Golden Ratio):}

$$
\begin{aligned}
{[A B C D] } & =[A B C]+[A C D] \\
& =\left[A B_{1} C\right]+[A C D] \\
& =\left[A B_{1} C D\right] \\
& =\left[A B_{1} D\right]+\left[C B_{1} D\right] \\
& =\frac{1}{2}\left|A B_{1}\right||A D| \sin \angle B_{1} A D+\frac{1}{2}\left|C B_{1}\right||C D| \sin \angle B_{1} C D
\end{aligned}
$$

Suatu pentagon sama sisi ABCDE, diketahui $|A B|=a$ dan $|A D|=b$. Buktikan bahwa $\varphi=\frac{b}{a}=\frac{1+\sqrt{5}}{2} \quad\left(\varphi=\frac{b}{a}\right.$ disebut golden ratio).

\section{Bukti:}




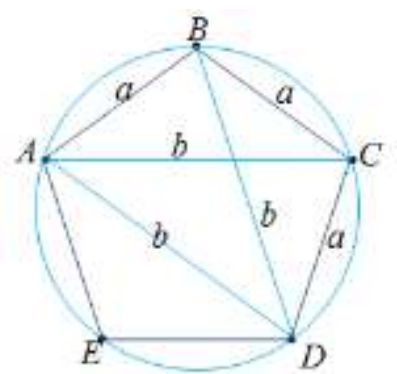

Gambar 4

Suatu segi-lima, titik-titik sudutnya dapat ditempatkan pada suatu lingkaran yang sama, sehingga jika titik A dihubungkan dengan D diperoleh segiempat siklik dan memenuhi aturan Ptolemy yaitu $b^{2}=a^{2}+a b$, sehingga

$$
\begin{aligned}
& \qquad \frac{b^{2}}{a^{2}}=\frac{a^{2}+a b}{a^{2}} \\
& \left(\frac{b}{a}\right)^{2}-\frac{b}{a}-1=0 \\
& \text { Maka diperoleh } \\
& \frac{b}{a}=\frac{1+\sqrt{5}}{2}
\end{aligned}
$$

\section{TEOREMA STEWART}

Dalam geometri, cevian adalah setiap segmen garis dalam segitiga dengan salah satu titik ujung pada titik dari segitiga dan titik ujung lainnya pada sisi di depannya. Perhatikan Gambar 5, AD merupakan satu contoh cevian dalam segitiga ABC.

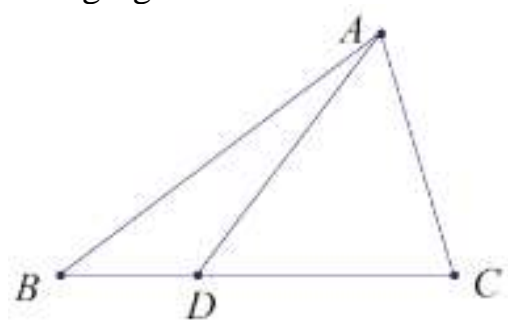

Gambar 5

Panjang dari cevian dapat ditentukan dengan menggunakan Teorema Stewart berikut.

\section{Teorema Stewart:}

Misalkan ABC suatu segitiga dan D titik sebarang pada segmen BC (gambar), maka $|A B|^{2}|C D|+|A C|^{2}|B D|=|B C|\left(|A D|^{2}+|B D \| C D|\right)$

\section{Bukti:}

Dengan menggunakan aturan cosinus pada segitiga ABD diperoleh

$\cos \angle A D B=\frac{|A D|^{2}+|B D|^{2}-|A B|^{2}}{2|A D||B D|}$.

Begitu pula pada segitiga ACD diperoleh

$\cos \angle A D C=\frac{|A D|^{2}+|C D|^{2}-|A C|^{2}}{2|A D||C D|}$.

Karena $\angle A D B+\angle A D C=180^{\circ}$, maka $\cos \angle A D B+\cos \angle A D C=0$ 


$$
\begin{aligned}
& \frac{|A D|^{2}+|B D|^{2}-|A B|^{2}}{2|A D \| B D|}+\frac{|A D|^{2}+|C D|^{2}-|A C|^{2}}{2|A D \| C D|}=0 \\
&|C D|\left(|A D|^{2}+|B D|^{2}-|A B|^{2}\right)+|B D|\left(|A D|^{2}+|C D|^{2}-|A C|^{2}\right)=0 \\
&|A B|^{2}|C D|+|A C|^{2}|B D|=|C D|\left(|A D|^{2}+|B D|^{2}\right)+|B D|\left(|A D|^{2}+|C D|^{2}\right) \\
&=\left|C D \left\|\left.A D\right|^{2}+\left|C D \left\|\left.B D\right|^{2}+\left|B D \left\|\left.A D\right|^{2}+|B D \| C D|^{2}\right.\right.\right.\right.\right.\right. \\
&=\left|C D \left\|\left.A D\right|^{2}+\left|B D \left\|\left.A D\right|^{2}+\left|C D \left\|\left.B D\right|^{2}+|B D \| C D|^{2}\right.\right.\right.\right.\right.\right. \\
&=|A D|^{2}(|C D|+|B D|)+|C D \| B D|(|B D|+|C D|) \\
&=|A D|^{2}|B C|+|C D\|B D\| B C| \\
&|A B|^{2}|C D|+|A C|^{2}|B D|=|B C|\left(|A D|^{2}+|B D \| C D|\right)
\end{aligned}
$$

\section{Contoh Masalah:}

Buktikan jika ABC suatu segitiga dan D titik pada segmen BC sehingga AD merupakan suatu segmen garis berat maka:

$$
|A D|^{2}=\frac{2\left(|A B|^{2}+|A C|^{2}\right)-|B C|^{2}}{4}
$$

\section{Bukti:}

Karena $\mathrm{AD}$ merupakan cevian pada segitiga $\mathrm{ABC}$ maka dengan menggunakan Teorema Steward diperoleh:

$$
|A B|^{2}|C D|+|A C|^{2}|B D|=|B C|\left(|A D|^{2}+|B D \| C D|\right)
$$

Karena $\mathrm{AD}$ merupakan garis berat maka $2|B D|=2|C D|=|B C|$, sehingga diperoleh

$$
\begin{aligned}
|A B|^{2}|C D|+|A C|^{2}|B D| & =\mid B C\left(|A D|^{2}+|B D| C D \mid\right) \\
|A B|^{2}|B D|+|A C|^{2}|B D| & =\mid B C\left(|A D|^{2}+|B D|^{2}\right) \\
\left(|A B|^{2}+|A C|^{2}\right) B D \mid & =\mid B C\left(|A D|^{2}+|B D|^{2}\right) \\
\left(|A B|^{2}+|A C|^{2}\right) B D \mid & =2 \mid B D\left(|A D|^{2}+|B D|^{2}\right) \\
\left(|A B|^{2}+|A C|^{2}\right) & =2\left(|A D|^{2}+\frac{|B C|^{2}}{4}\right) \\
\left(|A B|^{2}+|A C|^{2}\right) & =2|A D|^{2}+\frac{|B C|^{2}}{2} \\
|A D|^{2} & =\frac{2\left(|A B|^{2}+|A C|^{2}\right)-|B C|^{2}}{4}
\end{aligned}
$$

\section{TEOREMA CEVA}

Teorema Ceva sering dikaitkan dengan insinyur Italia Giovanni Ceva, yang pada 1678 diterbitkan karyanya De lineis rectis. Tapi teorema ini terbukti jauh sebelumnya oleh Yusuf AlMu'taman bin Hud, seorang raja abad kesebelas dari Zaragoza.

\section{Teorema Ceva:} Gambar 6):

Misalkan $\mathrm{AD}, \mathrm{BE}, \mathrm{CF}$ tiga cevian dari segitiga $\mathrm{ABC}$. Berikut ini adalah ekuivalen (lihat 
(1) $\mathrm{AD}, \mathrm{BE}, \mathrm{CF}$ konkuren; yaitu, garis-garis ini melewati titik yang sama.

(2) $\frac{\sin \angle A B E}{\sin \angle D A B} \cdot \frac{\sin \angle B C F}{\sin \angle E B C} \cdot \frac{\sin \angle C A D}{\sin \angle F C A}=1$

(3) $\frac{|A F|}{|F B|} \cdot \frac{|B D|}{|D C|} \cdot \frac{|C E|}{|E A|}=1$

\section{Bukti:}

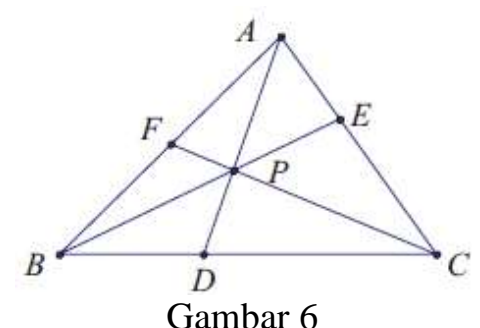

Diasumsikan bagian (1) AD, BE, CF berpotongan, dengan kata lain garis-garis ini melewati titik yang sama, benar. Kita asumsikan bahwa segmen $\mathrm{AD}, \mathrm{BE}$, dan $\mathrm{CF}$ bertemu di titik $\mathrm{P}$. Menerapkan aturan sinus pada segitiga $\mathrm{ABP}$, sehingga diperoleh

$\frac{\sin \angle A B E}{\sin \angle D A B}=\frac{\sin \angle A B P}{\sin \angle P A B}=\frac{|A P|}{|B P|}$

Demikian juga, diterapkan aturan sinus untuk segitiga BCP dan CAP, diperoleh

$\frac{\sin \angle B F C}{\sin \angle E B C}=\frac{|B P|}{|C P|}$ dan $\frac{\sin \angle C A D}{\sin \angle F C A}=\frac{|C P|}{|A P|}$.

Dengan mengalikan kesamaan-kesamaan yang diperoleh maka didapat

(2) $\frac{\sin \angle A B E}{\sin \angle D A B} \cdot \frac{\sin \angle B C F}{\sin \angle E B C} \cdot \frac{\sin \angle C A D}{\sin \angle F C A}=1$

Asumsikan bahwa bagian (2) adalah benar. Dengan menerapkan aturan sinus untuk segitiga $\mathrm{ABD}$ dan $\mathrm{ACD}$ diperoleh

$\frac{|A B|}{|B D|}=\frac{\sin \angle A D B}{\sin \angle D A B}$ dan $\frac{|D C|}{|C A|}=\frac{\sin \angle C A D}{\sin \angle A D C}$

Karena $\angle A D C+\angle A D B=180^{\circ}$, kita peroleh $\sin \angle A D C=\sin \angle A D B$. Dengan mengalikan kesamaan tersebut diperoleh

$$
\frac{|D C|}{|B D|} \cdot \frac{|A B|}{|C A|}=\frac{\sin \angle C A D}{\sin \angle D A B}
$$

Begitu halnya, kita peroleh

$$
\frac{|A E|}{|E C|} \cdot \frac{|B C|}{|A B|}=\frac{\sin \angle A B E}{\sin \angle E B C} \text { dan } \frac{|B F|}{|F A|} \cdot \frac{|C A|}{|B C|}=\frac{\sin \angle B C F}{\sin \angle F C A}
$$

Tiga kesamaan terakhir kita kalikan dan diperoleh

$$
\frac{|A F|}{|F B|} \cdot \frac{|B D|}{|D C|} \cdot \frac{|C E|}{|E A|}=1
$$

Asumsikan bahwa bagian (3) benar. Misalkan BE dan CF bertemu di P, dan misalkan sinar AP bertemu dengan segmen $\mathrm{BC}$ di $\mathrm{D}_{1}$ (Gambar 7). 


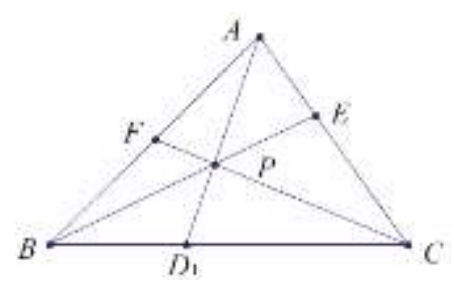

Gambar 7

Untuk menyatakan (1) benar, cukup menunjukkan bahwa $\mathrm{D}=\mathrm{D}_{1}$. Telah ditunjukkan sebelumnya bahwa jika (1) benar maka (3) juga benar maka karena cevian $\mathrm{AD}_{1}, \mathrm{BE}$, dan $\mathrm{CF}$ bertemu di $\mathrm{P}$ dan dengan asumsi awal (3) benar, diperoleh

$\frac{|A F|}{|F B|} \cdot \frac{\left|B D_{1}\right|}{\left|D_{1} C\right|} \cdot \frac{|C E|}{|E A|}=1=\frac{|A F|}{|F B|} \cdot \frac{|B D|}{|D C|} \cdot \frac{|C E|}{|E A|}$

Implikasinya $\frac{\left|B D_{1}\right|}{\left|D_{1} C\right|}=\frac{|B D|}{|D C|}$ $\mathrm{D}_{1}$. Sehingga berlaku pula (1).

Teorema Ceva dapat digeneralisasi bahwa titik perpotongan tidak harus berada di dalam segitiga, cevian dapat dianggap sebagai segmen dari titik sudut segitiga dan titik yang berada pada garis oleh perpanjangan sisi dihadapannya.

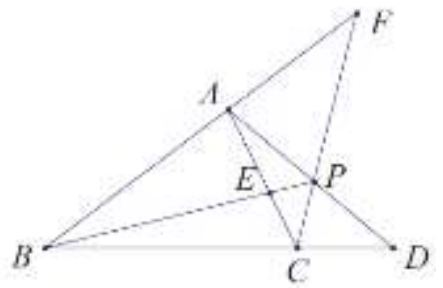

Gambar 8

\section{Contoh masalah:}

\section{Bukti:}

Buktikan bahwa ketiga garis bagi suatu segitiga konkuren.

$\mathrm{ABC}$ tersebut.

Misalkan ABC suatu segitiga dengan AP, BQ, dan CR adalah segmen garis bagi pada segitiga

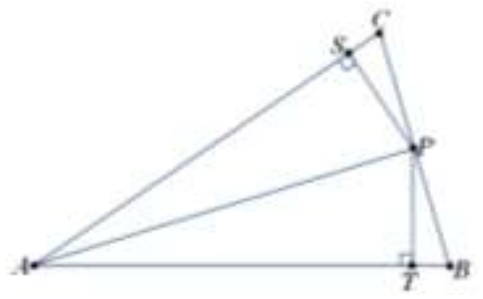

Gambar 9

Segitiga ATP kongruen dengan segitiga ASP, maka $|P T|=|P S|$. Dengan menerapkan aturan sinus diperoleh

$$
\begin{aligned}
& \frac{|B P|}{\sin 90^{\circ}}=\frac{|P T|}{\sin B} \text { atau }|B P|=\frac{|P T|}{\sin B} \\
& \frac{|P C|}{\sin 90^{\circ}}=\frac{|P S|}{\sin C} \text { atau }|P C|=\frac{|P S|}{\sin C} \\
& \text { Sehingga diperoleh } \frac{|B P|}{|P C|}=\frac{\sin C}{\sin B}
\end{aligned}
$$


Dengan jalan yang serupa juga diperoleh kesamaan

$\frac{|C Q|}{|Q A|}=\frac{\sin A}{\sin C}$ dan $\frac{|A R|}{|R B|}=\frac{\sin B}{\sin A}$

Ketiga kesamaan yang diperoleh kita kalikan sebagai berikut:

$\frac{|A R|}{|R B|} \cdot \frac{|B P|}{|P C|} \cdot \frac{|C Q|}{|Q A|}=\frac{\sin B}{\sin A} \cdot \frac{\sin C}{\sin B} \cdot \frac{\sin A}{\sin C}$

$\frac{|A R|}{|R B|} \cdot \frac{|B P|}{|P C|} \cdot \frac{|C Q|}{|Q A|}=1$

Berdasarkan Teorema Ceva maka AP, BQ, CR konkuren.

\section{TEOREMA MENELAUS}

Teorema Menelaus, dinamai dari seorang matematikawan dan astronom Yunani yaitu Menelaus dari Alexandria. Teorema ini tentang segitiga dalam geometri datar. Sementara teorema Ceva menyangkut konkurensi garis, teorema Menelaus tentang kolinearitas dari titik Menelaus.

Teorema Menelaus:

Diberikan segitiga $\mathrm{ABC}$, misalkan $\mathrm{F}, \mathrm{G}, \mathrm{H}$ masing-masing merupakan titik pada garis $\mathrm{BC}$,

$\mathrm{CA}, \mathrm{AB},\left(\right.$ Gambar 10). Maka F, G, H kolinear jika dan hanya jika $\frac{|A H|}{|H B|} \cdot \frac{|B F|}{|F C|} \cdot \frac{|C G|}{|G A|}=1$
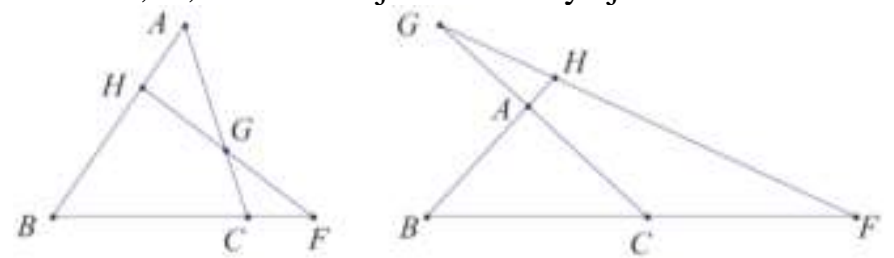

Gambar 10

Bukti:

Dengan menerapkan aturan sinus pada segitiga $\mathrm{AGH}$, diperoleh $\frac{|A H|}{\sin \angle A G H}=\frac{|G A|}{\sin \angle G H A}$ $\frac{|A H|}{|G A|}=\frac{\sin \angle A G H}{\sin \angle G H A}$

$\frac{|B F|}{|H B|}=\frac{\sin \angle B H F}{\sin \angle H F B} \quad \frac{|C G|}{|F C|}=\frac{\sin \angle G F C}{\sin \angle C G F}$

Dengan mengalikan tiga kesamaan terakhir memberikan hasil yang diinginkan $\frac{|A H|}{|H B|} \cdot \frac{|B F|}{|F C|} \cdot \frac{|C G|}{|G A|}=1$

\section{Contoh Masalah:}

Misalkan $\mathrm{ABC}$ suatu segitiga siku-siku, siku-siku pada $\mathrm{B}$ dan $|A B|:|B C|=3: 2$. Jika titik $\mathrm{P}$ berada pada perpanjangan $\mathrm{BC}$ dengan $|B C|:|C P|=2: 1$ dan $\mathrm{R}$ berada pada segmen $\mathrm{AB}$ dengan $|A R|:|R B|=1: 2$. Jika garis PR memotong memotong segmen AC di titik $\mathrm{Q}$, tentukan $|A Q|:|Q C|=$ $\cdots$.

\section{Penyelesaian:}

$\mathrm{ABC}$ suatu segitiga siku-siku, siku-siku pada $\mathrm{B}$ dengan $|A B|:|B C|=3$ : 2 . Jika titik $\mathrm{P}$ berada pada perpanjangan $\mathrm{BC}$ dengan $|B C|:|C P|=2: 1$ dan $\mathrm{R}$ berada pada segmen $\mathrm{AB}$ dengan $|A R|:|R B|=$ 1: 2 . 
karena Q merupakan perpotongan PR dengan AC maka P, Q, dan R kolinear (Gambar 11).

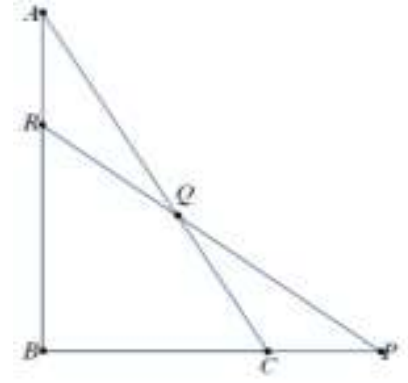

Gambar 11

Berdasarkan Teorema Menelaus, berlaku $\frac{|A R|}{|R B|} \cdot \frac{|B P|}{|P C|} \cdot \frac{|C Q|}{|Q A|}=1$. Karena $|B C|:|C P|=2: 1$ maka $\frac{|B P|}{|P C|}=\frac{3}{1}$, begitu juga $|A R|:|R B|=1: 2$ maka $\frac{|A R|}{|R B|}=\frac{1}{2}$ sehingga $\frac{1}{2} \cdot \frac{3}{1} \cdot \frac{|C Q|}{|Q A|}=1$. Maka diperoleh $|A Q|:|Q C|=3: 2$.

\section{KESIMPULAN}

Segitiga sebagai kajian dalam geometri datar, berkembang dalam deduksi formalnya dan menjadi dasar perkembangan dalam bidang lain dalam geometri datar. Salah satu kajian dalam segitiga yang sangat popular adalah Teorema Phytagoras. Banyak kajian lain terkait segitiga pada bidang datar, diantaranya kajian tentang cevian, yaitu segmen garis dalam segitiga dengan salah satu titik ujung pada titik dari segitiga dan titik ujung lainnya pada sisi di depannya. Kajian terhadap cevian melahirkan beberapa teorema, di antaranya: Teorema Stewart yang

\section{DAFTAR PUSTAKA}

[1] Andreescu, Titu, dan Feng, Zuming. 2005. 103 Trigonometry Problems: From the Training of the USA IMO Team. Boston. Birkhauser.

[2] Binatari, N. \& Gunarto, D.. 2007. Panduan Menguasai Soal-Soal Olimpiade Matematika Nasional dan Internasional. Yogyakarta. Indonesia Cerdas

[3] Sembiring, Suwah. 2002. Olimpiade Matematika SMA. Bandung. Yrama Widya.

[4] Wikipedia. 2012. Ceva's theorem. (online). menyajikan hubungan antara sisi-sisi segitiga dengan cevian dalam segitiga tersebut, Teorema Ceva dan Teorema Menelaus dimana Teorema Ceva menyangkut konkurensi cevian, sedang Teorema Menelaus tentang kolinearitas dari titik-titik tertentu pada masing-masing perpanjangan sisi segitiga.

Selain itu kajian lain tentang segiempat siklik melahirkan suatu teorema yang dikenal dengan Teorema Ptolemy atau Teorema Ptolemeus yang mengungkap keterkaitan antara diagonal-diagonal segiempat siklik dengan sisi-sisi segiempat siklik tersebut.

\section{(http://en.wikipedia.org/wiki/Ceva's} theorem, diakses 26 November 2012).

[5] Wikipedia. 2012. Cevian. (online). (http://en.wikipedia.org/wiki/Cevian, diakses 26 November 2012).

[6] Wikipedia. 2012. Menelaus' theorem. (online). (http://en.wikipedia.org/wiki/ Menelaus'theorem , diakses 26 November 2012).

[7] Wikipedia. 2012. Stewart's theorem. (online). (http://en.wikipedia.org/wiki/ Stewart'sTheorem, diakses 26 November 2012). 